\title{
Methodology Analyses of Contextual Landscape Urbanism with Case Study in Different Periods
}

\author{
Qianyi ZHU * \\ No.8 Bolin, Xiakou, Nan'an District, Chongqing, 400072, China \\ katherineqyzhu@gmail.com *
}

Keywords: Landscape urbanism, Contextual landscape, Ecological urbanization, Infrastructure urbanism, Methodology, Postmodernism

Abstract. This paper analyzes contextual landscape urbanism in different periods via two typical cases. And it explains the reasons that we conserve characteristic and contextual factors in landscape urbanism. Paper claims that accompanying city expanding, it is necessary and important to keep urban's unique historical feature in order to construct an identified city. According to two cases study, it illustrates the methods for keeping contextual elements while satisfying modern urbanization. Meanwhile, it is possible that ecological urbanism and concrete construction can work together through appropriate design.

\section{Introduction}

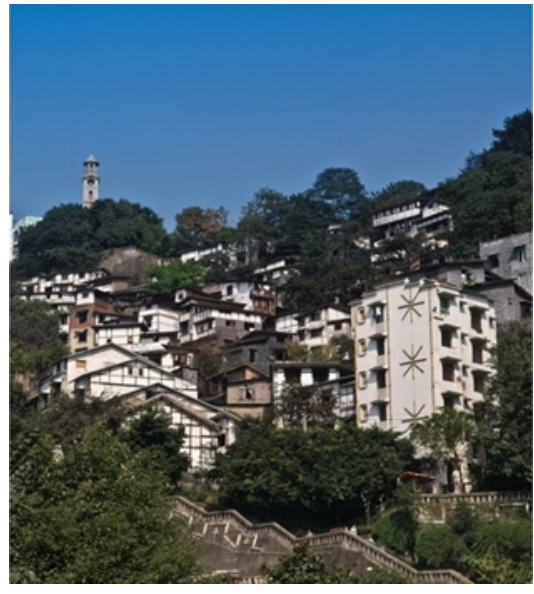

Fig. 1, Shibanpo District

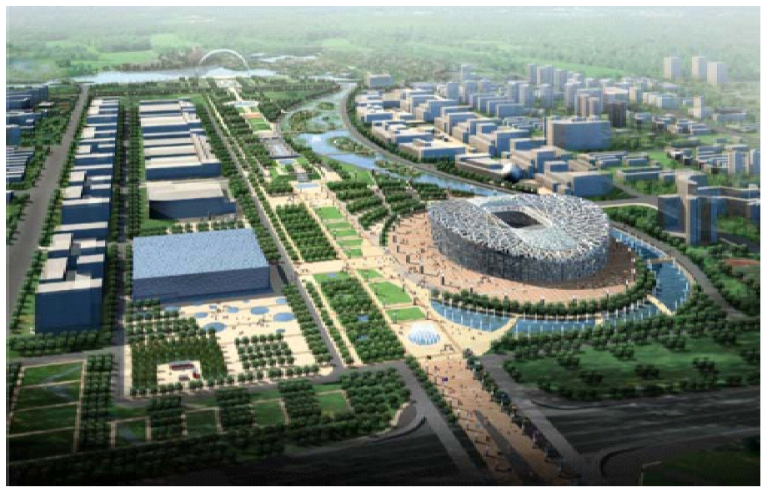

Fig. 2, the Beijing Olympic Park

The photos (Fig. 1, Fig. 2) above show two typical cases of contextual landscape urbanism in different periods. The town in Figure 1 is named Shibanpo locating in the heart center of Chongqing city, China, which was constructed during the middle of last century. Shibanpo district is an old residential community beside the Yangzi River showing the traditional style of Chongqing native residence. Figure 2 shows the planning of the Beijing Olympic Park what was published by OCOG of 2008 Beijing. The primary landscape planned by Beijing Tsinghua Urban Planning \& Design Institute and SASAKI was completed in 2008. Beijing Olympic Park is established for 2008 Beijing Olympic Games locating on the fifth ring in the right north of Beijing, China. The two cases are constructed in different periods of China, in where different cultural heritages exist. Although those cases has individual background, process of forming and constructed methods, they both represent contextual landscape urbanism.

Accompanying urban developing, we have several advanced urbanization methodology for modern cities' fast sprawl. Globalization, meanwhile, brings cities of China many cases of strong modernism from developed countries. We cannot deny the achievement of modernism as that mentioned by Daniel Z. Sui, "scholars pursuing research under the banner of the Chicago School share a common theoretical framework (urban/ human ecology) and generally accepted methodological procedures to validate and replicate their claims. That is why the Chicago School has contributed enormously to our 
understanding of how cities work and has exerted far-reaching influences in numerous branches of the social sciences.' [1] And we indulgent into the modernity for the functional opinion, succinct form, classical glass wall and so on. Postmodernity, sometimes, gets sarcasm for its intended inserting of significant symbol that it is actually parochial comprehending. Really, landscape urbanization bias contextualism cares and works well on modern cities' functional requirements. Furthermore, it is able to make the city to be cognizable and does not conflicted with ecological development.

\section{Case Introduction}

Shibanpo. Chongqing is a mountainous city, located in the center of China, where two rivers embrace which are Yangzi River and Jialing River. High humidity, because of the rivers, houses request typology there to be accessible for the wind in case of mugginess, which we call it 'board style'. In the past, houses always were along the contour lines (Fig. 3) and founded climbing mountain for undeveloped constructed technology. Then it forms right style for local environment and native residential condition, what is the limitation of urbanization too to some extent. Shibanpo district is this kind of residential community. As the particular geography condition of Chongqing, houses in Shibanpo district are constructed to line the hillside of devolution and face to the water body. That could be recognized as the primordial 'Riverview Dwelling', which is one of nowadays' famous and luxury residential house in Chongqing.

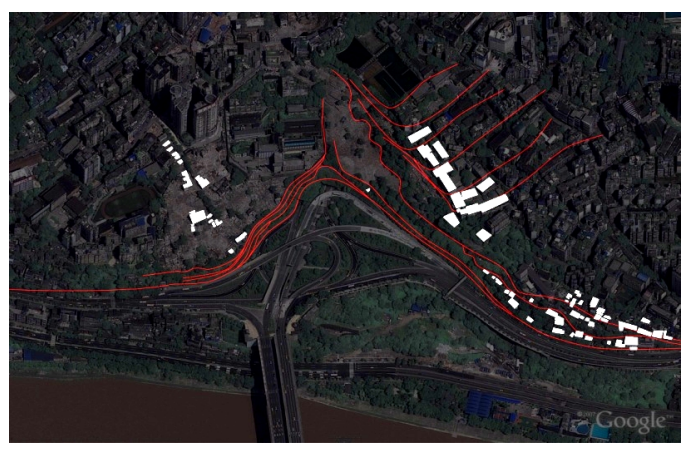

Fig. 3 Houses in Shibanpo are along the contour lines

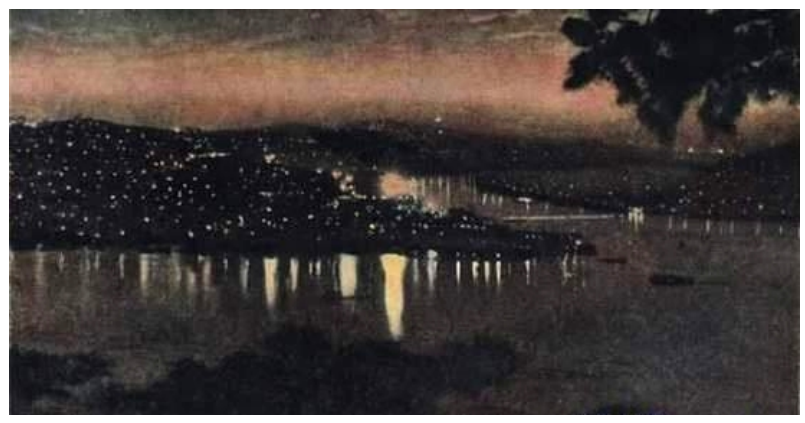

Fig. 4 Old view of Shibanpo

Shibanpo site backs on alp and looks on the river. The buildings sprawl the brae, line the waist of the mountains, superpose on each other and disappear at the side hill. They never touch the peak of the mountains and step on the bank of river. At night, the lights profile the mountains as groups of stars while others are hided in the dark (Fig. 4).

Buildings in Shibanpo is unique and celebrated Chongqing's 'Stilted House' which is the wooden house supported by the wooden pillar. In Chongqing, huge typographical change brings difficulty to find supported flat for builds. Moreover, the geological condition in Chongqing is unyielding rock (iron ore) which is hard to dig. The stilted houses cling to the escarpment, supported each other and stand on several wooden pillars. This kind of architecture could be retrospected to East Han Dynasty as the particular folk residential building. Its structure is the rudiment of the frame structure (girder and columniation). Shibanpo do shows the dwellers' wisdom relating urbanization when it faced to natural conditions.

Beijing Olympic Park. The planning of Beijing Olympic Park is not only satisfies functions of Olympic Game facilities, but also emphasizes extending the traditional central axis. The historical south-north axis is the greatest axis in urban construction history. The ancient structures such as celebrated Tiananmen Square, Forbidden City and Jingshan Park are situated on the axis and determine the axis to be great important (Fig. 5). The axis has witnessed the changes of Beijing and carries the symbol and memory of history, culture and politics. Beijing Olympic Park site is at the north end of the axis, which deals with tremendous challenge of continuing the culture and historical context. China had a long period of antique feudatories and absolute monarchy society, and Beijing was the capital in latest 600 years' of archaic China. Emperors announced that they were the sons of heaven in order to 
emphasize the important status in the country. Therefore, they constructed the royal palaces on the central land of the city facing to south. The buildings used by emperors were at the right center axis and
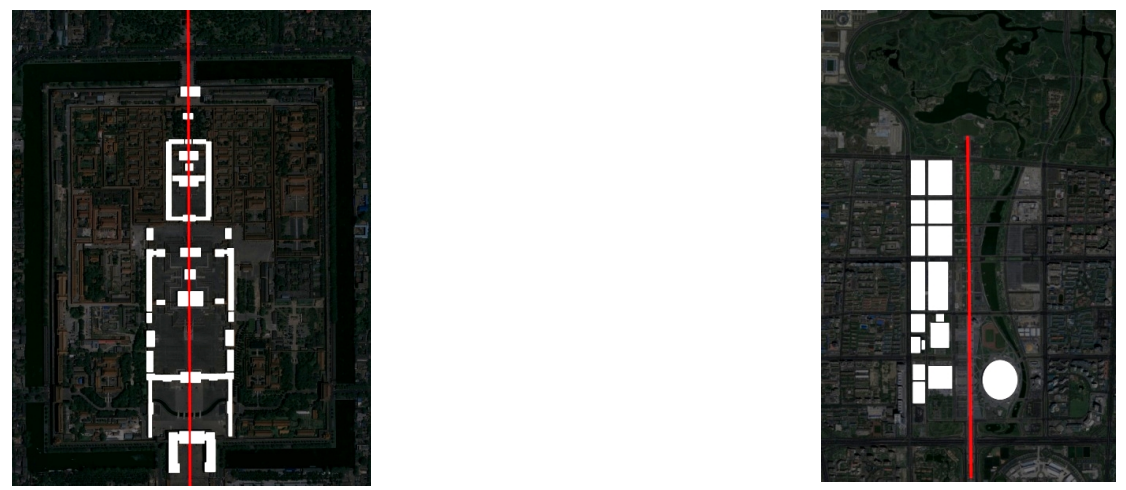

others were ordered on two sides of the axis. There is an access inside the

Fig. 5 Forbidden City

Fig. 6 Beijing Olympic Park

palace which connects all the central buildings and matches the central axis of the city (Fig. 6). That uses to be emperor's path what only the emperor could walk on. Sovran expressed the sovereign authority in this way. Nowadays, the axis is still the central axis and essence of Beijing city, what means something different. People of Beijing adore the axis line because of the national idiosyncrasy. 2008 Beijing Olympic Games brought urban to the fifth ring of Beijing city. So that is really aware and reasonable to take the urbanization by extending the axis.

\section{Case Study for Landscape Urbanism}

Shibanpo. In the beginning, persons needed dwelling building. So they built the residential house one by one adhering the cliff. Then, because of the characteristic typography, people constructed paths to approach the residential community. These paths should be the initial infrastructure for the site (Fig. 7). Accompanying the accomplishing of the public infrastructure, increasing human moved here. Urbanization in Shibanpo has happened like that and deals with natural handicap while Chongqing has accidented landform that such a symbol urbanism was.

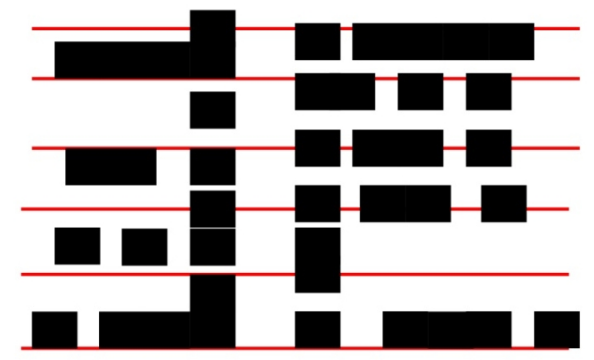

Fig. 7 Arrangement Logic of Shibanpo

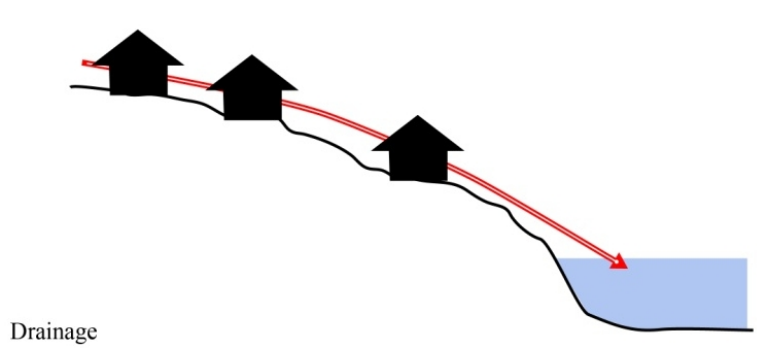

Fig. 8 Drainage of Shibanpo

Shibanpo's urbanization and great landscape view stand for a practical result of living experience. Everything here is reasonable which emerged from the typography, climate and residential living. Because of that, the form of Shibanpo's urbanization has several positive aspects. First of all, the master planning of the residential community is not from any 'professional design' but natural and native conditions, so that the construction is economical and suitable for the typography. The buildings line the contour what could save huge quantity of work to modify the land, and are drawn to the nearest material that decrease engineering cost. Moreover, the house typology within bidirectional sloping rooftop is good for piping rains while Chongqing frequently has rain shower. The water dropping from the rooftree will continue to fall down along the brae naturally, then inserts into the river finally (Fig. 8). That whole process was running normally till comprehensive infrastructure net in front of the community has been accomplished. Even now, notwithstanding the drain system works, water runs in 
the same way as before in some parts of the site. Here has its folk principle to carry on which was founded practically and rationally, and this is the natural infrastructure and landscape urbanization. Furthermore, the ventilation in the community is enough to control the micro-climate inside. The arrangement in Shibanpo district is like vein what is organic with reserves accesses for wind. Absolutely, this kind of establishment is also from the experience, that Chongqing city is a broiling megacity now where has extremely high temperature in summer. Most of dwellers living in Chongqing city have to use air-conditioning system to decrease the indoor temperature, what people living in Shibanpo, contrastively, less rely on. They open the windows and doors to get the natural cool wind. Ironically, some master plans do not work better on the micro-climate, no matter they are announced having professional designs from scientific calculations, metaphysics reckon and aesthetic thinking. Most important, natural disasters like flood and earthquake, cannot destroy the building because of the urban tending towards up. The urbanization here never touch the water, because people know that the river will swell every summer and they stop urban sprawling before the right point. That is why urbans like Shibanpo constructed beside the water body could survive from flood. Sarcastically, for several decades passed, we still have towns flooded where are founded following modern official planning principle. Finally, the urbanization like Shibanpo is shaped by nature, such as mountains and water bodies that you would never feel strange or ugly to its morphological sprawling and extending until the modern city center was established.

In the same time, there are obviously weakness of this kind of urbanization. Although the mountains shape the urban wonderfully on morphology, the existing obstacle still forecloses free urbanization to some extent. It seems like that the nature has already depicted the frame for people where they should stop and continue stretching. Secondly, the urbanization would occupy increasing green space while it sprawls. Human settlements must took over natural activities and impropriate part of the natural space despite people do not have to flat land to support the traditional stilted house in Chongqing. Primarily, Shibanpo's kind of construction is right extend on the hillside, as what Beatley said: cities can be fundamentally greener and more natural. Indeed, in contrast to the historic opposition of things urban and things natural, cities are fundamentally embedded in a natural environment. They can, moreover, be re-envisioned to operate and function in natural ways - they can be restorative, re-nourishing, and replenishing of nature, and in short like natural ecosystems: cities like forests, like prairies, like wetlands (Timothy Beatley, 2000)[2]. If there is only natural urbanization as Shibanpo, urban and ecological space are not themselves any more neither. Another one, the buildings support each other while they effect on each other. People try to connect the urban to be one holistic thing. The community likes Shibanpo district has not been destroyed by the earthquake mostly because of the ironbound geologic of Chongqing. Theoretically, the morphology of stilted house is like a box which is not steady enough when it faces to the geological tragedy.

Beijing Olympic Park. For culture consideration, the axis brings the local traditions and lifestyle to the rural area. Reciprocally, the new landscape urbanization continue the historic, unique and characteristic Beijing city, what is right one kind of methods for contextual urbanism. The planners propose the space as chessboard on the both axis which is planned as an organized line in Beijing Olympic Park. As we know, Chinese emperors in the antic times arranged the cities as chessboard model in order to manage the society with straightforward convenient method such as they could identify the level of different roads then publish the principle to limit the dwellers' activity, and it was easy to calculate the area of each block when the emperor favored land to any prince as encouragement (Fig. 9) [3]. That layout accentuated the sovereign of imperial power and emerged aesthetics in order. Beijing Olympic Park follows this kind of organic order with some renovation. There is no architecture but a linear landscape locating on the axis in the Beijing Olympic Park, which architectures stand by. The transformation of the pattern illustrates that there is no seignior age any more but peace, opening, freedom. The only one stands at the axis is the forest garden which is rising up and seems commanding the entire area. However, the area is designed for modern life, although the landscape in the Olympic Garden is claiming the traditional symbol. That is why the site contains traditional culture and also satisfies for the development of new lifestyle patterns. 


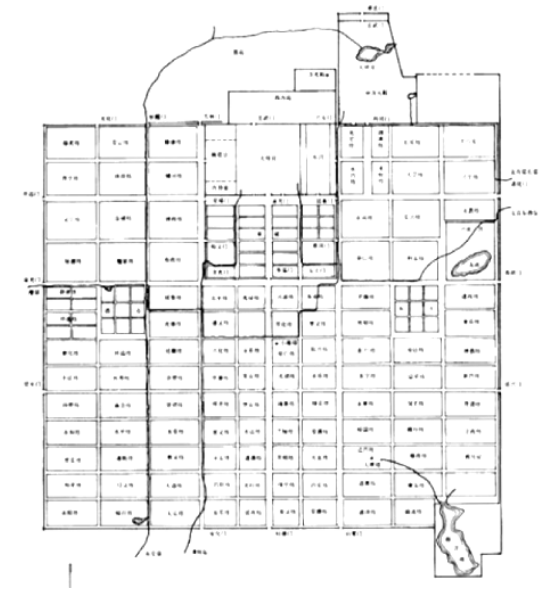

Fig. 9 Chang'an City of Tang Dynasty

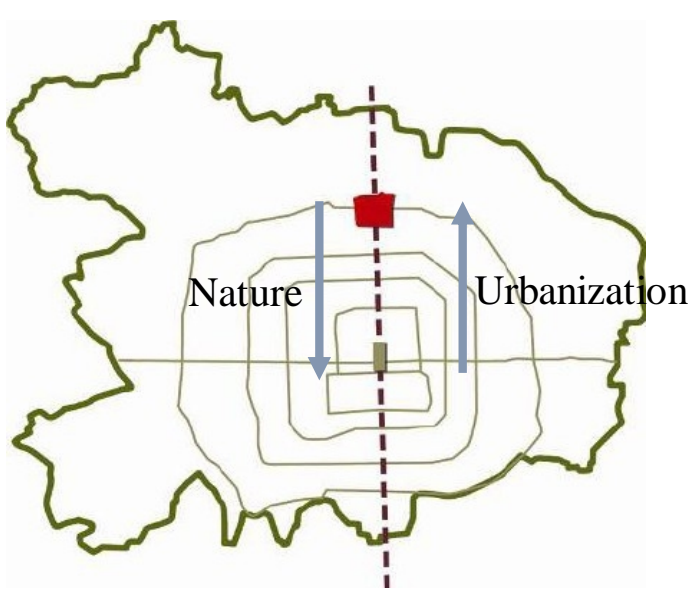

Fig. 10 Axis of culture and ecological in Beijing

Beijing Olympic Park's axis dose not only bring urbanization to the rural area, but also insert nature back to the city center (Fig. 10). Nowadays, the expressed urbanization in Beijing brought large quantity of concrete into the city center. Accompanying rapid urbanization and increasing population of Beijing, huge quantity of large-scale construction and development are carrying on and upsurge in traffic volumes is coming. In the same time, the problems like old urban infrastructure, water shortage and diminishing open green space are devouring the city. The whole Beijing city is being eaten up by concrete. For ecological consideration, the axis inserts natural resources into the city including good climate, vegetation, water, multiple landform, and clean energy resources as solar and wind. Designers arrange a forest park at the end of the Olympic area which is connected with the city center. Then the role of the axis is significant that bring green space to the city, so that the new landscape urbanization is able to improve abominable condition of the old city center.

\section{Comparative Dimension}

Ecological Consideration. The popular conception of ecological design as reconstructing 'native' environments is not only founded upon illusory and contradictory ideas about a non-cultural 'nature,' but also displays a remarkably non-ecological intolerance of alternative viewpoints and processes of transmutation (terms such as foreign and exotic betray an exclusivity and privileging of the natives) (James Corner, 1997). Today, one may observe that 'ecology' is appropriated as much by corporate and media industries as by environmentalists, land-artists, or politicians. Although ecology has generally been understood as providing a scientific account of natural processes and their interrelationships, the fact that it also both describes and constructs various ideological positions to be taken with regard to nature points to a greater significance (James Corner, 1997). [4]

For Shibanpo, the original ecological condition is good and human use local material that does not exhaust the natural recourse. Now the green space and the residential site form a relationship like edge and center. [5] For Beijing Olympic Park, the green spaces complete a corridor from the existing one in the city center. The principles of traditional Chinese landscape art emphasize on appearing natural views even artificial landscape, in which the mountain and water forming are the most crucial elements. Beijing Olympic Park right brings many kinds of water body into the city including lake, wetland and rivulet. [6, 7]

Infrastructural Considerations. Stations and paths are together in a system as points and lines, beings and relations. And its number and disposition of stations and paths leads city to interesting 
rhythm. Or it might be the flow of messages passing through the lines. In another words, 'a complex system can be formally described... One might have sought the formation and distribution of the lines, paths, and stations, their borders, edges, and forms. But one must write as well of the interceptions, of the accidents in the flow along the way between stations... What passes may be a message, but static prevents it from being heard, and sometimes, from being sent.' (Michel Serres) $[8,9]$

For Shibanpo, there is no forecast related the infrastructure. People constructed houses and roads just because of their needs at that moment. The native urbanism got role that it can afford itself. The main form of infrastructure is path or a few roads, because they just attempted to connect themselves to others. When the path increased and assembled, they recognized that the center was formed. In this aspect, the natural infrastructure is weaker than the professional proposal, and is tinier than large-scale design and planning. As Beijing Olympic Park, everything is purposefully considered, calculated aforehand and demonstrated scientifically. Because the sports events and the size of the park, it is organized as protagonist in the area. $[10,11]$

Process or Implementation. Absolutely, Shibanpo can't extend anymore because of the new kind of urbanization coming. People, however, conserve the style of urbanism to show the native culture and transformation of urban in Chongqing. Nowadays, there are residents still living in the site with a typical traditional life style. That is the general condition of this kind of natural urbanization what is alive but stops sprawling. The other one, after dramatic international event, Beijing Olympic Park will become a public space locating beside some residential community. The story of the park is extremely similar as the relationship of wedding and marriage - the later far-flung period of using is the real challenge which is considered adequately by the designer.

\section{Conclusion}

Contextualism and desire for self-expression could be considered as the result of postmodernism. 'It is as if urbs, the bound city form of the past, could be considered without civitas, the social agreement to share that lost urban promised land.' (Ingersoll, 1986) [12]. We develop the cities in the same model while asking for characteristic idea. So what is the right particular point that could make the city to be distinguished from others? For a long time, we are searching the point, but embarrassed to follow the finesse [13]. Actually, the critique of postmodern urbanism boils down to a critique of consumption as double edged sword within market's potential for empowerment and social inequalities, so that there are resistances to carry on $[14,15,16]$. Contextual landscape, however, is based on a kind of cultural and public resource, that thing is unnecessary to be made complicated.

We have several methods to complete a contextual landscape unlike just drawing on the wall or lining letters by trees. The two cases above are representative examples of aware illustration of native context. First of all, we must have a comprehensive realizing to context. It is not only a logo or a symbol, but also is the status of the people who live in the place, the process of the residential forming, or the antique idea in people's belief and so on. Then, to express the mentally heritage via structure or layout and etc. [17] Absolutely, contextualism does not conflict to ecological urbanism in that way, and we cannot give definite conclusion yet that it is not sustainable for its consumption. [18, 19] Precisely the opposite, there are many factors of context deserving to emphasize, that we can recognize how amazing the city is.

If we are not short on food, we will want to self-expression. And the same, if we already have the ability to construct urban, it hopes to be unique and characteristic. Contextual landscape is an additional option which is not contradictory form to infrastructure urbanism and ecological urbanism working.

\section{Acknowledgements}

This work was financially supported by the 2011 Research Program of Chongqing Municipal Commission of Urban-Rural Development (201163) 


\section{References}

[1] SUI Daniel Z., 1999, 'Postmodern Urbanism Disrobed: Or Why Postmodern Urbanism Is A Dead End for Urban Geography’, Urban Geography, Vol. 20 No. 5, pp. 403-411.

[2] BEATLEY Timothy, Green urbanism: learning from European cities, Island press, Washington (D. C.), 2000.

[3] WU Zhiqiang, LI Dehua, Principles of Urban Planning (4 ${ }^{\text {th }}$ Edition), China Architecture \& Building Press, Beijing, 2010, P. 22.

[4] CORNER James. Recovering Landscape: Essays in Contemporary Landscape Architecture, Princeton Architectural Press, 1999, Ch, 4 (Things Take Time and Time Takes Things: The Danish Landscape/Steen A. B. Hoyer) P. 69-77.

[5] RUANO Miguel, Ecourbanism: sustainable human settlements: 60 case studies, Gili, Barcelona, 2000.

[6] RITCHIE Adam \& THOMAS Randall (eds.), Sustainable urban design: an environmental approach, Taylor and Francis, London, 2009.

[7] SHANNON Kelly \& MANAWADU Samitha, 'Indigenous Landscape Urbanism: Sri Lanka's Reservior \& Tank System', JoLA (Journal for Landscape Architecture) Autumn, 2007, P. 6-17.

[8] SERRES Michel, The Natural Contract, University of Michigan Press (English translation by Elizabeth MacArthur and William Paulson), 1995.

[9] ALLEN Stan, 'Infrastructural Urbanism', Points+ Lines Diagrams and Projects for the City (reprinted in On Landscape Urbanism, Center 14, University of Texas at Austin School of Architecture, 2007) 1999, pp. 174-181.

[10] FEYEN Jan \& SHANNON Kelly \& NEVILLE Matthew, Water and urban development paradigms: towards an integration of engineering, design and management approaches, CRC, Boca Raton, 2009.

[11] BURDETT Ricky \& DEYAN Sudjic, The endless city: the urban age project by the London School of Economics and Deutsche Bank’s Alfred Herrhausen Society, Phaidon, London, 2007.

[12] INGERSOLL Richard, 'Postmodern Urbanism: Forward into the Past', Christopher Alexander et al. A New Theory of Urban Design, Oxford University Press, 1987.

[13] TURNER Tom, City as Landscape: A Post Post-modern View of Design and Planning, Taylor \& Francis, London, 1995.

[14] FOSTER Hal, Ed.: The Anti-Aesthetic: Essays on Postmodern Culture, Bay Press, 1983

[15] FOSTER Hal, Recodings: Art, Spectacle, Cultural Politics, Bay Press, 1985.

[16] FOSTER Hal, the Return of the Real: The Avant-Garde at the End of the Century, MIT Press, 1996.

[17] J. B. JACKSON, 'Concluding with Landscapes', in J. B. Jackson (ed.) Discovering the Vernacular Landscape; New Haven: Yale University Press, 1984, pp. 145-158.

[18] WHEELER, Stephen M. \& BEATLEY, Timothy (eds.), Sustainable Urban Development Reader, Routledge Urban Reader Series, Routledge, London, 2009.

[19] PITTS, Adrian, Planning and Design Strategies for Sustainability and Profit: Pragmatic Sustainable Design on Building and Urban Scales, Architectural press, London, 2004. 